\title{
INVESTIGACIÓN/RESEARCH
}

\section{PROPUESTA PARA EL TRATAMIENTO EFICAZ DE LA VIOLENCIA DE GÉNERO}

Elena Bandrés-Goldáraz ${ }^{1}$ : Universidad de Zaragoza, España. bandres@unizar.es

\section{RESUMEN}

La violencia de género sigue siendo una lacra en la sociedad española a pesar de la promulgación de una ley integral y de la adopción de medidas judiciales. Las decisiones de autorregulación tomadas por parte de los medios de comunicación también han servido para añadir objetividad y neutralidad en este tipo de violencia. Sin embargo, siguen aumentando las muertes de mujeres a manos de sus parejas. Proponemos un cambio radical en la manera de informar para intentar que los medios generen un efecto disuasorio para futuros asesinos $y$, también, que provoquen una verdadera conciencia social contra este tipo de crímenes. Se trataría de crear un protocolo de actuación por el que el Ministerio del Interior suministre fotografías e imágenes del presunto culpable (tal y como se hace en otros casos de violencia), tanto en la comisaría como en su traslado a la cárcel. Además, los medios deberían adoptar pautas mucho más concretas de actuación que las que actualmente siguen dentro de sus códigos de autorregulación. Consideramos necesario dar a estas noticias un enfoque diferente ya que, sin imagen de los presuntos culpables y sin referencias a los castigos a los que se enfrentan, se está desnaturalizando el drama.

PALABRAS CLAVE: Violencia - género - tratamiento - medios - comunicación televisión.

\section{PROPOSAL FOR THE EFFECTIVE TREATMENT OF GENDER- RELATED VIOLENCE}

\begin{abstract}
\footnotetext{
${ }^{1}$ Autor correspondiente

Elena Bandrés-Goldáraz: Profesora Asociada, Universidad de Zaragoza, España.

Correo: bandres@unizar.es
}

Gender-related violence continues to cast a shadow on Spanish society despite the passing of a comprehensive law and the adoption of judicial measures that deal with 
such crimes. Self-regulation on the part of the media has helped give more objectivity to reports and stories on the topic. Yet the number of cases where women die at the hands of their husbands or partners continues to rise. We therefore propose a radical change in the way information is disseminated in this regard, not only to prevent more crimes, but also to generate real social awareness about this issue. We suggest the Ministry of the Interior to provide the media with photographs and/or videos of the accused while they are being held in the police station and in their prison cells, the way other criminal cases are treated. In addition, the media should take more concrete steps apart from those which they are observing in the current self-regulatory codes. We believe that news reports and documentaries that touch on this matter should take on a different focus, that is, to give a name and a face to the accused and to mention the punishment that is in store for them.

KEY WORDS: Violencia - género - tratamiento - medios - comunicación -televisión.

\section{INTRODUCCIÓN}

El objeto de este artículo es aportar un planteamiento diferente en el tratamiento informativo que llevan a cabo las empresas periodísticas, fundamentalmente televisivas, en los casos provocados por la violencia de género desarrollada en las relaciones de pareja. Se trata de solicitar la colaboración del Ministerio del Interior, a través de los Cuerpos de Seguridad del Estado con el fin de intentar que las noticias generen la conciencia social que actualmente no provocan y que se centren en la imagen de los culpables en lugar de en las víctimas, algo que actualmente no ocurre. Para llegar a las pautas sugeridas, se ha empleado la técnica de análisis de contenidos desde el punto de vista cualitativo, basado en la observación y análisis de las noticias emitidas, fundamentalmente, por las televisiones españolas TVE, Antena 3 TV y Tele 5, en 2009, 2010 y los tres primeros meses de 2011.

El concepto de violencia de género ejercida en la pareja suele ser confundido con el término violencia doméstica, por el hecho de suceder dentro del hogar, sin embargo muchas parejas en las que el hombre ejerció dicha violencia no convivían bajo un mismo techo. La violencia de género es un tipo de violencia ejercida contra la mujer, entendiendo por este concepto:

cualquier acción $u$ omisión intencional que dañe o pueda dañar a una persona porque se desvía de los estereotipos socialmente construidos. Como la violencia de género contra el hombre no es numéricamente significativa, habitualmente la expresión violencia de género se refiere sólo a la violencia contra la mujer. Hay diferentes tipos de violencia de género. La violencia contra la mujer en las relaciones de pareja, el tráfico sexual de mujeres o la mutilación genital femenina son algunas de sus formas. (Sanmartín, 2006)

Erradicar la violencia contra las mujeres es uno de los Objetivos de Desarrollo del Milenio fijados por Naciones Unidas. Ciento ochenta y nueve jefes de Estado y de 
Gobierno se comprometieron a cumplirlo para 2015. El Fondo de Desarrollo de las Naciones Unidas para la Mujer considera que es una "meta pendiente" de los Objetivos del Milenio, "aunque poner fin a la violencia contra las mujeres constituye una prioridad estratégica para lograr la igualdad de género y los objetivos en general".

En 1993, la Unión Europea, elevó a la categoría de prioridad política combatir la violencia contra la mujer ejercida en la sociedad. Esta decisión se tomó en el marco de la tercera Conferencia Ministerial sobre Igualdad entre Mujeres y Hombres, en la cual se perfilaron las estrategias para la erradicación de la violencia contra la mujer en la sociedad. Fruto de este acuerdo se crea, en 1996, el Instituto Europeo de la Igualdad de Género. La Resolución WHA49.25 de la Asamblea Mundial de la Salud declaró, en ese mismo año, la violencia como problema prioritario de salud pública proclamada por la OMS.

El informe del Parlamento Europeo de julio de 1997, la Resolución de la Comisión de Derechos Humanos de Naciones Unidas de 1997, y la Declaración de 1999 como Año Europeo de Lucha Contra la Violencia de Género, entre otros, fueron la antesala al programa marco puesto en marcha por el Consejo de Europa sobre la igualdad entre hombres y mujeres 2001-2005 y al respaldo del proyecto "respuestas a la violencia en la vida cotidiana de la mujer en una sociedad democrática". Fruto de ello, los países miembros empezaron a promulgar leyes integrales contra la violencia de género en un intento por desenmascarar lo que Bordieu (Bordieu, 2000,:p 12) llama "violencia simbólica contra las mujeres", la "violencia amortiguada, insensible e invisible para sus propias víctimas".

Y, ya en la tercera cumbre de Gobierno de los Estados miembros del Consejo de Europa, que tuvo lugar el 16 y 17 de mayo de 2005 en Varsovia, los Jefes de Estado anunciaron la decisión de erradicar la violencia contra las mujeres y los niños, incluida la violencia doméstica. En el Plan de Acción establecieron un grupo de trabajo para evaluar los avances a nivel nacional en la lucha contra la violencia contra la mujer y establecieron los instrumentos para cuantificar la evolución a nivel paneuropeo, con vistas a la elaboración de propuestas de acción.

\subsection{Medidas legales para frenar el problema}

Siguiendo la estadística del Centro Reina Sofía para el estudio de la violencia, entre 2000 y 2010 han sido asesinadas 704 mujeres en España, lo que supone una media de 70,4 mujeres cada año. A 15 de abril de 2011 han muerto asesinadas en España dieciocho mujeres, veintiuna en la misma fecha de 2010. Estas cifras abocan a referirnos a la violencia de género como un claro ejemplo de terrorismo contra las mujeres. Setecientos cuatro casos en diez años frente a los 828 asesinatos provocados por la banda terrorista ETA desde 1960. Por eso convenimos con Sánchez Rodríguez (2008) cuando dice que "el tratamiento informativo de las noticias relacionadas con la violencia machista es un nuevo reto social comparable, por ejemplo, al tratamiento de la información relacionada con el terrorismo, inmigración.". 
En España, el 71,91\% de las mujeres víctimas de la violencia de género son españolas y el $28,09 \%$ son extranjeras, fundamentalmente europeas y latinoamericanas. La prevalencia en las jóvenes ha aumentado un 103,23\% en los últimos diez años. Y, como último dato, (Sanmartín, 2006) hay que destacar que la gran mayoría de los asesinos son detenidos.

España fue pionera en promulgar una ley integral, muy ambiciosa, para luchar con la violencia de género en 2004. En su primer apartado, esta Ley dice que:

La violencia de género no es un problema que afecte al ámbito privado. Al contrario, se manifiesta como el símbolo más brutal de la desigualdad existente en nuestra sociedad. Se trata de una violencia que se dirige sobre las mujeres por el hecho mismo de serlo, por ser consideradas, por sus agresores, carentes de los derechos mínimos de libertad, respeto y capacidad de decisión.

Esta ley aborda el problema desde los tres escenarios en los que tiene que hacerse la prevención de esta violencia: el educativo, el de la publicidad y medios de comunicación, y el sanitario. Delimita el campo de actuación aunque da por supuesto un hecho cuya constatación diaria dista de ser evidente y es cuando dice que la violencia de género "produce un rechazo colectivo y una evidente alarma social". Sin embargo, nos preguntamos cómo se mide la alarma social cuando no existen más indicadores que las encuestas de opinión elaboradas por el Centro de Investigaciones Sociológicas (CIS). Consideramos que sí generan alarma, pero no social.

El rechazo generado en la sociedad, conocedora de estos casos a través de los medios de comunicación, puede presuponerse o puede constatarse a través de estudios de investigación.

La Ley 5/2008 del Parlamento de Cataluña cambió el término violencia de género por violencia machista "porque el machismo es el concepto que de forma más general define las conductas de dominio, control y abuso de poder de los hombres sobre las mujeres y que, a su vez, ha impuesto un modelo de masculinidad que todavía es valorado por una parte de la sociedad como superior. La violencia contra las mujeres es la expresión más grave y devastadora de esta cultura, que no solo destruye vidas, sino que impide el desarrollo de los derechos, la igualdad de oportunidades y las libertades de las mujeres. Por ello el derecho no puede tratar este problema social desde una perspectiva falsamente neutral, sino que los instrumentos legales deben reconocer esta realidad para eliminar la desigualdad social que genera.

La descompensación entre las relaciones de género sólo se podrá eliminar a través de la eliminación de los estereotipos sexistas y la igualación de los mecanismos de poder entre hombre y mujer. Dos objetivos que sólo emergerán por medio de la educación, a largo plazo, en el sistema educativo y familiar y, a corto plazo, a través de los medios de comunicación como agentes sociabilizadores y conformadores de la realidad, porque no habrá: 
jamás un plan o una ley que sea eficaz mientras la sociedad en su conjunto no experimente una serie de cambios (...) en la familia, que es el escultor que te va cincelando y el primer contexto de socialización, al que le siguen la escuela y los medios de comunicación audiovisual, que son configuradores de formas de vida (Sanmartín, 2006)

\section{METODOLOGÍA}

La presente investigación fue realizada bajo el método teórico: histórico-lógico exponiendo la correspondencia entre los aspectos históricos que han condicionado un contexto en el cual los medios de comunicación no logran el desarrollo de programas disuasorio para futuros asesinos $\mathrm{y}$, también, que provoquen una verdadera conciencia social contra este tipo de crímenes. Se trataría de crear un protocolo de actuación más efectiva para incidir en la disminución de la violencia contra el género femenino. De esta manera los medios los medios deberían adoptar pautas mucho más concretas de actuación que las que actualmente siguen dentro de sus códigos de autorregulación. Consideramos necesario dar a estas noticias un enfoque diferente ya que, sin imagen de los presuntos culpables y sin referencias a los castigos a los que se enfrentan, se está desnaturalizando el drama.

Para la construcción de la situación problémica, así como para el análisis y discusión de los resultados se empleó el método de análisis documental

\section{ANÁLISIS Y DISCUSIÓN}

\section{1 ¿Generan los medios alarma social en la transmisión de estas noticias?}

El Centro de Investigaciones Sociológicas de España (CIS) analiza la percepción de los problemas que tiene la sociedad española, a través de los barómetros. Las encuestas que realiza el CIS cada mes (exceptuando el mes de agosto) sirven "para medir el estado de la opinión pública en relación con la situación política y económica del país y sus perspectivas de evolución". Realizan encuestas entre una muestra de la población española con diferentes asuntos. Una de las preguntas consiste en enumerar los "tres problemas principales que existen actualmente en España". Las personas entrevistadas tienen que decir las tres cuestiones problemáticas que, a su juicio, son las más relevantes. La violencia contra la mujer aparece en decimonoveno lugar, salvo en 2010 y en enero de 2011 fecha en la que escala un puesto aunque disminuye el porcentaje de personas que lo consideran uno de los principales problemas a pesar del aumento de mujeres muertas 
Tabla 1. Opiniones respecto a la violencia contra la mujer en España

\begin{tabular}{|c|c|c|}
\hline \multicolumn{3}{|c|}{ LA VIOLENCIA CONTRA LA MUJER EN ESPAÑA } \\
\hline $\begin{array}{l}\text { Porcentaje de } \\
\text { lo considera un }\end{array}$ & $\begin{array}{l}\text { nas que } \\
\text { ma importante }\end{array}$ & Mujeres asesinadas \\
\hline Enero 2011: & $1,4 \%$ & 7 \\
\hline Diciembre 2010: & $1,4 \%$ & 75 \\
\hline Diciembre 2009: & $2.7 \%$ & 60 \\
\hline Diciembre 2008: & $2.5 \%$ & 76 \\
\hline Diciembre 2007: & $3.0 \%$ & 72 \\
\hline Diciembre 2006: & $2.8 \%$ & 70 \\
\hline Diciembre 2005: & $3.0 \%$ & 63 \\
\hline Diciembre 2004: & $4.4 \%$ & $69^{*}$ \\
\hline Diciembre 2003: & $3.0 \%$ & 70 \\
\hline Diciembre 2002: & $1.9 \%$ & 52 \\
\hline Diciembre 2001: & $3.3 \%$ & 46 \\
\hline Septiembre 2000: & $1.3 \%$ & 51 \\
\hline
\end{tabular}

Fuente: (Elaboración Propia a partir de los datos del CIS)

*Los picos más altos se dan en marzo de 2004 con un 11.7 y en junio y julio con un 8.0. Se produce un aumento en la percepción como problema social, al haber sido asesinadas seis mujeres en un solo mes. Todas ellas, con edades comprendidas entre los 22 y los 59 años, fueron asesinadas por sus parejas. En uno de los casos, el agresor mató también a su suegra e hirió a una hermana de la víctima, de 11 años.

La violencia contra la mujer en España sólo es percibida como un problema social por el 2,6\% de los entrevistados. Por encima de este problema se encuentra: 
Violencia - género - tratamiento - medios - comunicación -televisión

\section{Pregunta 7}

¿Cuál es, a su juicio, el principal problema que existe actualmente en España? ¿Y el segundo? ¿Y tercero? (RESPUESTA ESPONTANEA) (MULTIRRESPUESTA).

\begin{tabular}{lr}
\hline El paro & 82.4 \\
\hline Las drogas & 6 \\
\hline La inseguridad caudadana & 7.3 \\
\hline El terrorismo, ETA & 7.4 \\
\hline Las infraestructuras & .6 \\
\hline La sanidad & 3.6 \\
\hline La vivienda & 4.4 \\
\hline Los problemas de indole económica & 53.1 \\
\hline Los problemas relacionados con la calidad del empleo & 2.7 \\
\hline Los problemas de la agricultura, ganaderia y pesca & 2 \\
\hline La corrupción y el fraude & 2.4 \\
\hline Las pensiones & 4.2 \\
\hline La clase politica, los partidos politicos & 20.6 \\
\hline La Administración de Justicia & 1.0 \\
\hline Los problemas de indole social & 3.9 \\
\hline El racismo & 2.2 \\
\hline La inmigración & 12.8 \\
\hline La violencia contra la mujer & 1.4 \\
\hline Los problemas relacionados con la juventud & 1.4 \\
\hline
\end{tabular}

Figura 1. Centro de Investigaciones Sociológicas (CIS) BARÓMETRO DE ENERO Estudio n ${ }^{\mathrm{O}} 2.859$. Enero 2011

Por lo tanto, sirvan estos datos para asegurar que la sociedad española no ve la violencia de género como un problema que cause alarma social, ni siquiera ante el aumento en el número de casos. Quizás debamos achacar esta ausencia de alarma social a la percepción de este tipo de violencia como un "asunto" perteneciente a la esfera íntima de la pareja y que, como tal, debe ser resuelto por sus miembros sin intervención externa alguna. En una investigación del Centro Reina Sofía acerca de las actitudes y conductas de la ciudadanía ante el problema de la violencia de género en las relaciones de pareja, se encontró que prácticamente todos los encuestados (exactamente, el 98,5\%) tenían conocimiento de la existencia de este grave problema. Sin embargo, sólo la mitad habían intentado hacer algo al respecto. Un tercio de quienes no habían hecho nada aducían como justificación que este tipo de violencia es un “asunto privado" (Sanmartín, Iborra \& Martínez, 2010).

\subsection{Mejorar la eficacia de los códigos deontológicos de autorregulación}

Desde comienzos de esta década, los medios de comunicación españoles han intentado abordar de la manera más eficaz posible los estándares informativos a los que someterse a la hora de redactar una noticia de estas características. "Se ha pasado de hablar únicamente de casos particulares (hechos concretos de violencia doméstica, lo que serían "noticias episódicas") a afrontar una cobertura más amplia, relacionando unos hechos con otros y tildándolos de problemática social -"noticias temáticas"- (Berganza, 2003). El asesinato de Ana Orantes, en diciembre de 1997, a manos de su marido, supuso el punto de partida para la autorregulación de los propios medios de comunicación. En 2002, el Instituto Oficial de Radio y Televisión elaboró el documento "De lo privado a lo público. Tratamiento informativo de la 
violencia contra las mujeres". Fue suscrito por las principales cadenas de televisión y sirvió como base para la elaboración de un decálogo que recogió las pautas para el tratamiento informativo de dichas noticias en cada medio. En estos códigos presentes en las principales televisiones españolas, así como en las diferentes asociaciones de la prensa y colegios profesionales se enumeran una serie de principios que especifican la manera con la que tiene que dar la información un periodista.

Un objetivo que está pensado para ser cumplido y "para que la autorregulación no sea entendida como una mera cuestión utópica” (Agejas, 2007).

En cuanto a prensa escrita, el diario Público fue el primero en elaborar un código deontológico para este tipo de casos, en enero de 2008. Los códigos buscan huir del sensacionalismo y del morbo y pretenden fomentar la conciencia social contra este tipo de casos. Pero, siete años después de aprobarse la Ley contra la Violencia de Género en el parlamento español, varios años después de que los medios iniciaran su autorregulación particular para tratar informativamente estos temas y tres años después de que las empresas periodísticas se comprometieran a mejorar este tipo de información, nos encontramos con que los medios de comunicación, especialmente la televisión, se encuentran muy lejos de fomentar la conciencia social de condena, necesaria e imprescindible, desde nuestro punto de vista, para generar la percepción de que este tipo de violencia no es un asunto privado, sino un gravísimo problema público.

El 29 de noviembre de 2007, la entonces vicepresidenta del Gobierno Español, María Teresa Fernández de la Vega, inició una serie de contactos con los principales medios de comunicación, tras el impacto generado por la muerte de Svetlana Orlova a manos de su expareja, Ricardo Navarro. Éste la asesinó días después de acudir engañada al programa de Antena 3 TV "El diario de Patricia", en donde su ex novio le pidió volver a reiniciar su relación, algo que ella no aceptó. La indignación vertida en los medios de comunicación por este caso generó los encuentros entre el Gobierno Español y los principales medios de comunicación, para intentar autorregular la emisión de noticias sobre violencia de género.

Las empresas de televisión públicas, RTVE y las integradas en la FORTA, junto con las privadas pertenecientes a la Unión de Televisiones Comerciales Asociadas (UTECA) se comprometieron a insertar en sus informaciones el teléfono de denuncia del maltrato, 016; a hacerse eco de las sentencias que condenaran a un agresor; a enfatizar que los daños infligidos no sólo afectan a la mujer sino a toda la sociedad; a crear un Comité de Expertos; a cambiar las rutinas profesionales y los estereotipos y a crear un Defensor de la Igualdad en las televisiones públicas." Las televisiones acordaron que las informaciones se centrarían en la víctima y que nunca justificarían las acciones del varón, también ofrecerán datos sobre las consecuencias penales de la agresión e informarán de las sentencias condenatorias bajo el asesoramiento de un grupo de expertos", (Diario Público,29/11/2007). 
Sin embargo, tras observar y analizar las noticias emitidas en televisión, podemos constatar que no se ha conseguido alcanzar el objetivo marcado, ya que estos acuerdos no se cumplen en su totalidad. Sólo TVE ha mantenido de forma constante la inserción del teléfono contra el maltrato en la noticia que informa sobre un nuevo caso de violencia de género. También esta cadena se ha caracterizado por la puesta en marcha de programas especiales, la emisión de películas y la creación del portal http://www.rtve.es/noticias/concienciados/igualdad-genero/ para concienciar contra esta lacra. Tanto Tele 5 como Antena 3 TV no suelen poner de forma sistemática este teléfono. Por otro lado, las cadenas de televisión no realizan un seguimiento de los casos de condena a los agresores. No dan información sobre las "consecuencias penales de la agresión", salvo en una noticia emitida el 31 de enero de 2011 en TVE, en la que se dice en el texto de la información que "hasta noviembre de 2010 los presos por violencia de género superaban los 5.000". Es la primera vez que una noticia de televisión, de estas características, informa sobre el número de personas encarceladas por este motivo, aunque el dato se alejó del aportado por la subdirección de Tratamiento y Gestión Penitenciaria del Ministerio del Interior, que cifró el número en 6.539 personas.

Ninguna televisión ofrece datos e informaciones sobre "las consecuencias penales de la agresión ni informan de las sentencias condenatorias bajo el asesoramiento de un grupo de expertos". El único seguimiento que se lleva a cabo por las cadenas es, a lo sumo, la detención, días después, del presunto asesino.

En España, no se está produciendo la condena social en la opinión pública, no al menos con la intensidad que originan otro tipo de asesinatos. A pesar de todas las recomendaciones recogidas en los códigos específicos de autorregulación, las informaciones vertidas siguen sin conseguir los objetivos marcados. Parte de las causas de esta situación la encontramos en que el relato audiovisual presenta mensajes contradictorios letales para la generación y percepción de la condena social. Se informa sobre estos hechos (Martínez, 2011: 320-321) "más y mejor que hace una década antes de la proliferación de los códigos deontológicos (...) pero los periodistas no parecen conocer las recomendaciones o, al menos, no han profundizado en ellas. Incluso en el caso de la ley, hay un conocimiento vago al respecto, inconcreto, y por tanto sus recomendaciones no se plasman en el trabajo cotidiano: la teoría, o bien no se conoce, o al menos no se pone en práctica".

\subsubsection{Las contradicciones en el mensaje}

En la redacción y emisión de este tipo de noticias, se dan diversas contradicciones que dificultan la correcta percepción de la información. El primer mensaje contradictorio es el generado por los propios medios de comunicación al relegar la noticia a la sección de sociedad, lo que supone que aparezca en los informativos en el puesto decimonoveno o vigésimo en la emisión de los vídeos. En este caso, el lugar sí que importa. Si bien es cierto que este tipo de noticias se emiten, desde hace ya tiempo, en los titulares de los informativos, la decisión de los propios medios de aplazar su emisión hasta las últimas posiciones, justo antes de los deportes, genera una 
devaluación de la consideración que tienen esas muertes. De esta manera, no se puede cumplir con el acuerdo suscrito en diciembre de 2011, entre Gobierno y empresas de comunicación, de "enfatizar que los daños infligidos no sólo afectan a la mujer sino a toda la sociedad".

En la prensa escrita aparecen también en las secciones de sociedad, así como en las radios, aunque salgan en portada. Eso no hubiera ocurrido si la víctima hubiera sido una persona asesinada por una banda terrorista. En estos casos, todos los medios de comunicación, además de abrir sus informativos y ediciones en papel con el atentado, dan esta información como primera noticia, tras los titulares. En la prensa escrita, además de aparecer en la mitad de la portada, abren la sección de España. Este tratamiento en la ubicación de la noticia (que es el correcto, por otra parte) no es el que reciben los casos de terrorismo contra las mujeres, a pesar de que produce en España un $303,8 \%$ más de casos. El tratamiento de la violencia machista es relegado a la categoría de "suceso" (IORTV, 2002). En estas posiciones en las escaletas, es muy difícil generar conciencia social y que la ciudadanía lo considere una amenaza contra la sociedad civil.

El País, martes, 16/06/2009. En el periódico de mayor difusión en España, un nuevo caso de terrorismo contra la mujer. No aparece en portada y es relegada a una columna en la página 37.

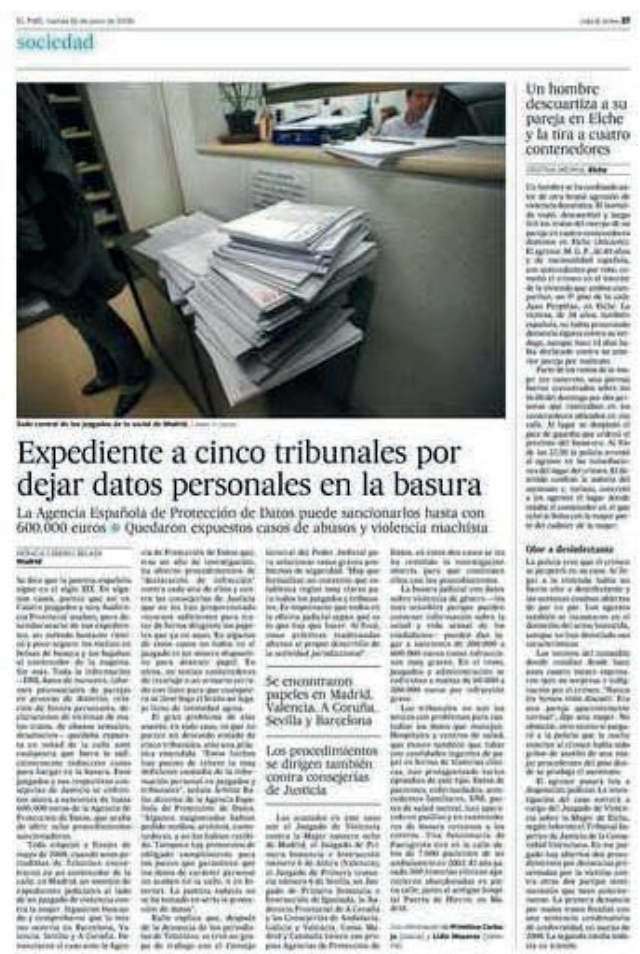

Figura 2. El País, martes, 16/06/2009.Portada 


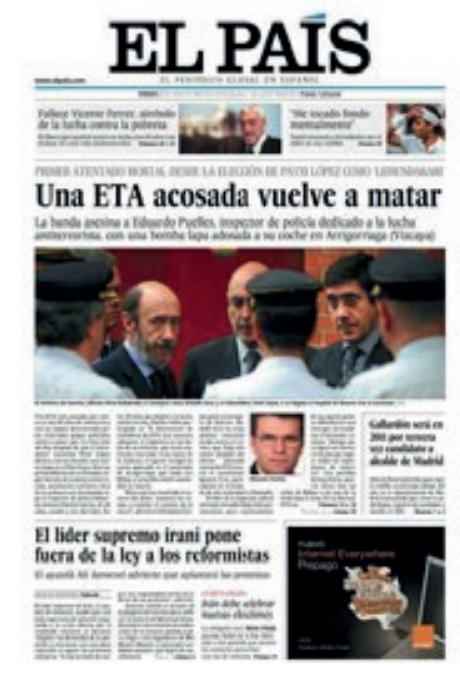

Figura 3. El País, domingo, 20/06/2009.

La noticia de la mujer asesinada en Granada, el 21 de marzo de 2011, no aparece ni en titulares ni en lugares destacados, sino en la sección de sucesos.

La segunda contradicción se produce con la ausencia del (presunto) asesino en las imágenes. Sin la identificación visual del agresor, se diluye el concepto racional de "culpabilidad". De esta manera, parece que la noticia es más bien relatada como un género de ficción, al no contar con la existencia explícita de una identificación directa del autor del crimen. En el estudio de Sánchez Aranda, Berganza y García Ortega (2003: 150), “en más de la mitad las noticias, el 54,1\%, desconocemos quién ha perpetrado la agresión (...) se intenta preservar el anonimato de los verdugos, ya que se evita dar sus datos personales y se comentan otros que hacen más difícil su identificación". Ahora esta situación ha empeorado, ya que en televisión no se incorpora el nombre y apellido del asesino, salvo que el caso se alargue en el tiempo ${ }^{2}$. No aparece ni el nombre completo ni la imagen del presunto asesino, mientras que sí se incluye la foto de la víctima y su nombre, aunque no su apellido. La dignidad de la víctima sigue, por tanto, siendo maltratada informativamente y la presencia de la mujer queda de nuevo oculta. "Sólo dos de cada diez personas que aparecen en las noticias, son mujeres, y lo hacen ocultas por el lenguaje, (sin apellidos, sin indicar su cargo, en función del marido, etc) y reforzando los estereotipos (como famosas, como víctimas de violencia..." (Ruiz Seguín, Loscertales y Núñez, 2008) ${ }^{3}$.

Esta forma de presentar a la víctima y a su verdugo continua formando parte de una rutina profesional que se torna especialmente dañina para la víctima. Tomando como ejemplo el caso de violencia de género del 21 de marzo de 2011, emitido en Tele 5,

\footnotetext{
2 Este fue el caso de la muerte de Laura Alonso a manos de su ex novio, Javier Cruz, a finales de agosto de 2009.

${ }^{3}$ Loscertales Abril, F. y Nuñez Domínguez, T. (coord.). Los medios de comunicación con mirada de género Sevilla, 2008. Instituto Andaluz de la Mujer.
} 
Antena 3 TV y TVE, los tres informativos empiezan con las imágenes del cuerpo de la víctima cuando es sacado por los trabajadores de la funeraria. Tele 5 inicia el vídeo diciendo: "Este era el momento en el que los trabajadores de la funeraria sacaban el cuerpo sin vida de Natividad. Tenía 62 años y estaba a punto de divorciarse. Su marido presuntamente la apuñaló. Después se acercó hasta este bar, donde confesó el crimen".

Las imágenes que acompañan a estas frases son un plano medio del momento en el que sacan del portal de la vivienda el cuerpo de la víctima, un plano general de la misma escena y un plano corto en el que se ve el momento en el que se introduce el cuerpo en un féretro de metal. El siguiente plano refleja el bar al que acudió el presunto asesino que, una vez más, carece de nombre. Sí aparece el teléfono 016

Los testimonios que aparecen en este vídeo son del dueño del bar, que repite la frase que supuestamente dijo el asesino confeso, del portavoz de la policía local y de varios vecinos que sólo aportan detalles escabrosos del crimen.

En Antena 3 TV, empieza el vídeo con este texto:

Natividad, de 62 años, ha muerto presuntamente a manos de su marido a primera hora de la mañana, en la vivienda en la que ambos convivían. Según fuentes de la investigación, su agresor que ya ha sido detenido, le apuñaló en el cuello con un cuchillo de cocina y le golpeó la cabeza con un martillo.

Las imágenes en este primer bloque, antes de la inclusión del testimonio de un vecino, narran el momento en el que sacan de la vivienda el cuerpo sin vida de la mujer y lo meten al féretro, igual que en Tele 5. Antena 3 incluye imágenes de una concentración en repulsa por este nuevo caso de violencia.

TVE lleva esta información a imágenes, sin testimonios y sobre ellas, que narran el momento en el que sacan el cuerpo de la víctima del bloque de viviendas, la presentadora del informativo dice:

En Granada, la policía ha detenido a un hombre de 62 años después de que confesara que había matado a su mujer. El hombre es un policía nacional jubilado. La mujer, también de 62 años, nunca había presentado una denuncia por malos tratos, aunque había estado separada durante un tiempo de su marido y luego había vuelto a convivir con él. Tenían dos hijos, uno de ellos guardia civil. Con la muerte de esta mujer son 15 las víctimas mortales por violencia de género en lo que llevamos de año.

Sí aparece el teléfono para denunciar el maltrato. En el informativo de las 21 horas, TVE sí que lleva esta información a vídeo cerrado, con la inserción del testimonio del portavoz de la policía local, que cuenta cuáles han sido las armas empleadas en el crimen. También recoge la manifestación contra el nuevo caso, que tuvo lugar ante las 
puertas del Ayuntamiento de Granada, así como una sobreimpresión del teléfono 016. Esta manera de redactar y editar las noticias refleja, por un lado, la doble victimización de la mujer asesinada. No sólo ha sido asesinada sino que, además, su cuerpo metido en una bolsa es víctima de la obscenidad que genera esa imagen. Por otro lado, la ausencia del asesino confeso, en este caso, elimina de la noticia el concepto de autoría. Psicológicamente no hay culpable si éste no aparece en pantalla, pero lo que sí se articula en la mente de cualquier mujer que esté pasando por una situación de maltrato, es que denunciar esa situación es sinónimo de muerte. Dos de las cadenas lo evidencian:

Este era el momento en el que los trabajadores de la funeraria sacaban el cuerpo sin vida de Natividad. Tenía 62 años y estaba a punto de divorciarse. Su marido presuntamente la apuñaló", (Tele 5). "Era usuaria del Instituto Andaluz de la Mujer que había venido en varias ocasiones pero nos pedía asesoramiento en materia jurídica porque su intención era divorciarse. El detenido pasará mañana a disposición judicial. (Antena 3 TV).

Informativamente hablando ha cambiado muy poco la situación desde el estudio de Sánchez Aranda, Berganza y García Ortega (2003:149) cuando dicen que el agresor apenas aparece en estas informaciones. "Mientras las víctimas aparecen en imágenes en un $29 \%$ de las informaciones, el agresor lo hace en un 3\%". Esta ausencia del relato audiovisual "como la pasividad o el no rechazo de este tipo de violencia beneficia siempre al maltratador", tal y como dice Raimunda de Peñafort, titular del Juzgado número 1 de Madrid contra la violencia de género, en una entrevista concedida a El País Digital el 25 de noviembre de 2005.

La tercera contradicción se da en la presentación de la posible ayuda a otras víctimas para huir de su agresor. La invitación permanente para denunciar los malos trato que se presenta con la aparición en pantalla del teléfono 016, no resulta muy recomendable cuando, de forma habitual, aparece en las noticias la enunciación del suceso (un hombre ha matado a su mujer, o a su ex mujer o a su pareja, etc...) y, a continuación, se narra la situación actual de convivencia, que es en la inmensa mayoría de los casos de separación o en trámites de hacerlo. ¿Qué mujer sometida a malos tratos accede a dejar a su maltratador, si tras ver en la televisión la noticia de una mujer asesinada por su pareja escucha la frase: "un hombre mató ayer a su mujer con un arma de fuego y después se suicidó. Según los vecinos estaban en trámites de separación" 4

La mujer que quiere salir de una situación de malos tratos, viendo los resultados de muerte de la víctima que llevaba varios años denunciando los hechos, según se informa en

\footnotetext{
43 RTVE, Dos nuevos casos de violencia de género. Noticia emitida el 05-10-2009 en el informativo de las 15 horas de TVE. Consultado el 16 de Marzo del 2011. Disponible en:

http://www.rtve.es/alacarta/videos/television/dos-nuevos-casos-violencia- genero/599454/.
} 
muchas noticias, preferirá seguir aguantando las palizas antes que abandonar a su maltratador. Para evitarlo, hay que ofrecer siempre una solución, tanto para el agresor como para la víctima, y eso, hoy en día, no se da en las noticias sobre violencia de género, "ya que la violencia masculina contra las mujeres es en la mayor parte de sus veces cotidiana y habitual. Las parejas que se acostumbran a esta forma de relación la integran en sus vidas y pueden seguir conviviendo con ella durante años" (Alberdi \& Matas, 2002).

Según el informe sobre el perfil del maltratador, elaborado para Instituciones Penitenciarias por Javier Fernández Montalvo y Enrique Echeburúa, (Matey, 2008) "se sabe que llevar más de 10 años casada, haber recibido malos tratos físicos habituales y amenazas de muerte, pertenecer a una clase social baja, haber abandonado a su agresor después de una larga convivencia y llevar separados de hecho menos de nueve meses son los principales factores de riesgo para las víctimas".

La cuarta contradicción se presenta con la imagen errónea, trasmitida tanto por los vecinos de la vivienda en donde se producen los hechos como por la imagen de las personas que intervienen como fuentes cualificadas (ministros/as, autoridades, policías...). Los testimonios de los primeros suelen aportar una aproximación a la descripción de los hechos o un testimonio en el que declaran que el agresor "era una persona absolutamente normal". Pero la imagen generada, en la mayoría de los casos, por los responsables políticos, personal sanitario, Cuerpos y Fuerzas de Seguridad, mientras hablan de la muerta de turno, no provocan la necesaria empatía para generar condena social

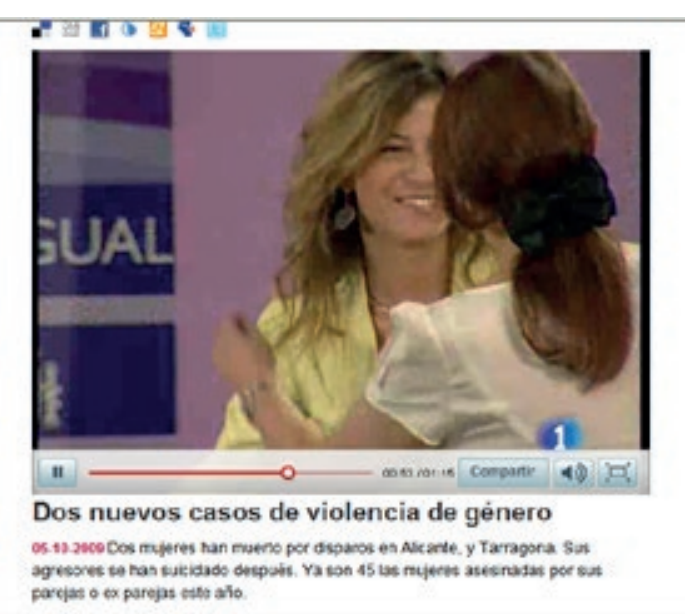

Figura 4. Programa donde han tratado el tema de violencia femenina.

Como ejemplos de contradicción entre la imagen y la voz en off del periodista nos encontramos con la imagen de la ex ministra española del desaparecido Ministerio de Igualdad, emitida en la noticia "Dos nuevos casos de violencia de género", el 5-102009. La voz en off que aparece en el mismo momento que esta imagen es la siguiente: "ella cincuenta. La ministra de Igualdad ha condenado los asesinatos. Aparece sonriente mientras saluda a una integrante de la mesa en la que se encuentra. 


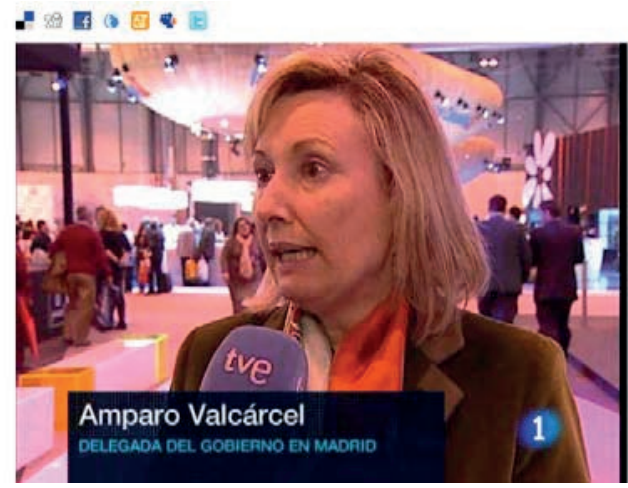

Figura 5. La ministra de Igualdad ha condenado los asesinatos.

Lo mismo ocurre con el testimonio de la ex ministra que aparece justamente a continuación de ese plano. Su imagen sonriente mientras hace las declaraciones de condena contradicen el mensaje hablado. Dice la ministra: "Vamos a seguir trabajando, poniendo recursos, poniendo toda nuestra voluntad encima de la mesa, toda la coordinación y sumando esfuerzos". En este caso, la ex ministra Bibiana Aído no ofrece "sentimientos" que transmitan expresos deseos de condena o rechazo. $\mathrm{Su}$ aparición en pantalla con un gesto risueño (gesto que evidentemente se hace de forma inconsciente) elimina cualquier elemento subjetivo de condena

El 21 de enero de 2010, Amparo Valcárcel, Delegada del Gobierno en Madrid, aparece en la noticia sobre la muerte de una mujer en la localidad madrileña de Brunete, con imagen seria pero "fría" y "aséptica", dice: "Una muerte provocada por el machismo criminal. Una muerte que no hemos podido evitar, eeh. No existía entre ellos denuncias previas y tampoco existía ninguna orden de alejamiento".

\subsection{Criterios objetivos para incorporar en las informaciones}

Tras analizar las diferentes noticias, emitidas fundamentalmente en los informativos de las 15 horas de las cadenas de TVE, Tele 5 y Antena 3 TV, concluimos que no se ha avanzado en lo sustancial a la hora de redactar las noticias para televisión para lograr una narración audiovisualmente eficaz. Consideramos que la presencia principal en un caso de violencia de género tiene que ser la del presunto asesino, cuando existan claros indicios sobre la autoría del crimen. Por ello, las noticias deben incluir la fotografía, tomada por la propia policía cuando detiene y ficha al presunto asesino. También debería introducirse en la noticia las imágenes del presunto agresor esposado y conducido a la comisaría de policía o a los juzgados. La primera noticia de un nuevo caso de muerte por violencia de género en 2010, en TVE, empezó con la imagen del presunto asesino esposado por la policía, imagen que se repitió nuevamente en otra parte del vídeo.

Hay ya medios que intentan obtener la imagen del presunto asesino a través del entorno de la víctima pero debe ser la policía quien la suministre. Enrique López, portavoz del Consejo General del Poder Judicial, solicitó en 2008 la colaboración de los medios de comunicación para terminar con esta lacra al decir durante el II Seminario 
sobre Nuevas Tecnologías y Violencia de Género: "La sociedad reclama a la administración de justicia más eficacia, y nosotros pedimos a los medios de comunicación más responsabilidad; que se impliquen en la lucha y en la prevención contra la violencia" (Sánchez Rodríguez, 2008). Pero la colaboración tendría que venir también por parte de la Policía y los Tribunales. El Ministerio del Interior debería suministrar las fotografías e imágenes del presunto agresor detenido por la policía, de la misma manera que se suministran las imágenes de otros terroristas fichados.

Velando en todo momento por la presunción de inocencia, la aparición de las fotos del presunto asesino fichado por la policía es vital para conseguir fijar en la mente del público la imagen de un asesino. Con tal fin, proponemos que se llegue a un acuerdo entre Ministerio del Interior y Medios de Comunicación (como ya se alcanzó en 2007 por parte de la Vicepresidencia del Gobierno) para que la policía facilite a los medios la imagen fotográfica del presunto asesino o permita la grabación audiovisual. La falta de imágenes que testifiquen que hay un castigo cuando se cometen estos crímenes ahonda en la percepción de la existencia de impunidad para con los culpables ya que no se informa de las penas a las que son condenados los culpables.

Por otro lado, la creatividad semántica debería estar supeditada a la descripción del maltratador y nunca al relato detallado del crimen ni de la víctima, ya que estas descripciones son los primeros peldaños para dar pie al sensacionalismo y al morbo.

En radio y televisión, por otra parte, se relatan las noticias en función del material recogido. Es decir, si un intento de asesinato cuenta con testimonios de la víctima y de parte del vecindario, además de los suficientes planos de recurso, parece merecer más tiempo dentro de la parrilla de la emisión del informativo, en detrimento del otro caso en el que sí se haya consumado el asesinato del que no hay testimonios ni apenas recursos.

Mientras los medios, fundamentalmente las televisiones ya que son los canales informativos que más audiencia arrastran, no valoren el tiempo dedicado a estas noticias en función de su importancia y no del material bruto conseguido, la ciudadanía tampoco podrá hacerse cargo de la dimensión del drama. Por eso, el mal uso de los mecanismos de la narrativa audiovisual puede desnaturalizar, muchas veces, un drama producido por la violencia de género. El mal uso de estos mecanismos convierte el drama en ficción, con la consiguiente desaparición de todos los mecanismos de condena y de censura social. Salvando las distancias, es a lo que Casasús (en Rojas, 2010) se refiere cuando dice que hay que utilizar de forma inteligente la imágenes y las palabras para adquirir un compromiso ético.

Quizás, en nuestra opinión, esta forma de actuar pueda estar convirtiendo a los medios de comunicación en motores de imitación en lugar de ser motores de sensibilización en contra de la violencia de género. Aunque un estudio de la Universidad de Alicante, publicado en octubre de 2009, asegure que informar sobre la violencia machista ayude a "prevenir nuevos crímenes" (Flotats, 2009). 
Otro de los efectos perniciosos del tratamiento actual supone la utilización de la violencia como único instrumento para solucionar frustraciones. El maltratador que ve reflejado su caso de riñas continuas, habituales desavenencias con su pareja, en prensa, radio y televisión, va a intuir la violencia como forma de amedrentamiento, como forma de legitimación de su actuación.

\subsection{Diez pautas para un tratamiento eficaz de la violencia de género}

Por todo lo que hemos expuesto anteriormente, proponemos estas pautas elementales para redactar y emitir una noticia de terrorismo contra la mujer:

1.- Una muerte por violencia de género debe ocupar siempre los titulares y la primera noticia del informativo o de la sección "España". Tiene que ser narrada como un delito contra los derechos humanos, igual que se hace con otros casos de terrorismo.

2.- La noticia debe centrarse en la exposición de los datos del agresor, en las características y personalidad de la persona agresora, en vez de los datos personales de la víctima. De esta manera se evitará caer en el morbo y en el sensacionalismo que genera la información volcada en la víctima, como por ejemplo, sobre una imagen del ataúd, la voz en off de la periodista dice: "Isabel luchó por vivir hasta el final", Tele 5, 3/09/09 (Detenido el presunto asesino de su ex pareja en Vélez-Málaga).

3.- Debe primar en la información la imagen del agresor esposado y en las dependencias policiales, nunca la de la víctima. (Debe prevalecer su presunción de inocencia, pero eso no es óbice para informar sobre el caso).

4.- Los testimonios de la familia y del vecindario que se aporten a la noticia, tanto escrita como audiovisual, deben reflejar un conocimiento real del agresor, por lo que los testimonios deben ser siempre de condena. No se deberán insertar testimonios sobre el agresor del tipo: "era una persona completamente normal", o "era una bellísima persona dulce y agradable, por lo menos con los vecinos", etc., ni sobre condiciones que puedan servir de atenuante como por ejemplo que hacer referencia al "estado de embriaguez en el que se encontraba el agresor" porque testimonios como estos corren el riesgo de exculparle desde una perspectiva social, al considerar que la agresión ha sido fruto de una enajenación mental transitoria o provocada por la ingesta de alcohol.

5.- Hay que ofrecer siempre, en la noticia, los testimonios de personas expertas en Violencia contra las Mujeres, como por ejemplo diversas asociaciones de mujeres, así como la opinión de policías, psicólogos y jueces, que deben hablar como profesionales representantes del estamento al que pertenecen y condenar los hechos.

6.- No hay que valorar en ningún momento la causa del delito. Se tienen que omitir definiciones y adjetivos como crimen pasional (Tele 5, 17/10/2009, "Muere una joven rumana apuñalada en Marbella"), celos (Tele 5, 9/09/2009, "Mata a tiros a su mujer y después se entrega"), etc. Hay que evitar datos subjetivos como "no pudo soportar el que su novia de 45 años pusiera fin a la relación", (Tele 5, 3/09/09, “Detenido el presunto asesino de su ex pareja en Vélez-Málaga”). 
También se exculpa psicológicamente al asesino si se dice frases como "las continuas crisis que soportaba la pareja", o "el matrimonio llevaba varios años con problemas de convivencia", o "al parecer, la pareja mantuvo una fuerte discusión", etc. También hay que eliminar los estereotipos de marginalidad y de nacionalidad, ya que los malos tratos se dan en todas las clases sociales. No se trata de convertir a los hombres en enemigos de las mujeres, sin de desterrar conductas patológicas con el fin de promover relaciones de igualdad entre sexos.

7- No describir el crimen. Ni las "cuchilladas que recibió la víctima en la espalda", ni las cuchilladas que le atravesaron el cuello", ni los gritos que profirió el agresor cuando asestó el golpe mortal a la víctima", etc. porque generan morbo y sensacionalismo. No mostrar imágenes en las que se vea el reguero de sangre dejado por la víctima, si no es con la foto del asesino inmediatamente después.

8- Especificar las penas a las que se enfrentará el presunto asesino e ilustrar esta información siempre con imágenes de cárceles.

9.- Recoger las declaraciones de condena contra ese crimen por parte de políticos y personas relevantes en la sociedad.

10.- Ofrecer siempre al maltratador y posible futuro feminicida una salida pacífica para terminar su fallida relación sentimental. Si bien es imposible generalizar las circunstancias de cada persona, lo que los profesionales llaman buscar la individualización científica, la información tiene que terminar con un cierre del tipo:"La sociedad ve con mejores ojos la disolución de una pareja antes que cualquier tipo de violencia para terminar una relación. Nadie se va a reír de un hombre por haber sido abandonado por su mujer, todo lo contrario".

Incluso conviene en esta parte de la noticia incluir una declaración de profesionales de la psicología para reafirmar esta tesis.

Dentro de esta información global sobre un nuevo caso de violencia de género, la siguiente noticia tendría que ser un reportaje sobre cómo viven los nuevos divorciados; un mini reportaje donde se muestre que un hombre puede vivir solo, sin la mujer con la que ha compartido sus últimos años. Que puede solucionarse sus necesidades domésticas más inmediatas como mantener la casa, cocinar, planchar, lavar y llevar una vida digna y plena.

\section{CONCLUSIONES}

La profesión periodística debe articular un protocolo de actuación claro, breve y conciso para informar sobre los casos de violencia de género. A tenor de las noticias emitidas en los dos últimos años, los códigos deontológicos adoptados por las diferentes televisiones españolas se muestran claramente insuficientes para abordar este tipo de información, ya que no generan la condena social que provocan otro tipo de asesinatos, también considerados como atentados contra los derechos humanos. 
Los periodistas necesitan disponer de medidas concretas que no dejen resquicio a la interpretación, ya que la urgencia por recabar imágenes e información en el lugar del crimen hacen olvidar los códigos deontológicos propios (que no son demasiado precisos) y los principios fundamentales acordados entre la Vicepresidencia del Gobierno Español y los principales medios de comunicación en noviembre de 2007.

Las noticias emitidas siguen sin informar del agresor; en algunos casos, se sigue justificando de manera encubierta el crimen y se sigue sin mostrar las consecuencias penales derivadas del asesinato de una mujer. No se articula una opinión favorable a la igualdad ni inspiran el cambio social contra la violencia de género, a pesar de ser las conclusiones adoptadas en dicha fecha.

Se hace imprescindible la colaboración con las Fuerzas de Seguridad para la obtención de las imágenes de los presuntos asesinos esposados y fichados por la policía, cuando las evidencias así lo demuestren. Sin estas imágenes, el relato audiovisual seguirá sin traspasar el ámbito privado y continuará desvaneciendo la tragedia personal de miles de mujeres en cuanto termine la emisión de las noticias. Estas informaciones seguirán perteneciendo al ámbito privado mientras sigan sin ocupar el primer lugar en los informativos y en las portadas de los periódicos. Si se sigue asociando la separación de la pareja con la muerte de la mujer y se continúa ofreciendo testimonios que introduzcan la enajenación mental transitoria dentro de frases como "crimen pasional" o "al parecer iba bebido", las informaciones periodísticas no contribuirán a erradicar la violencia de género a través de su faceta educadora a corto plazo. Si, además, los agentes políticos y sociales no condenan este tipo de terrorismo, tanto dialéctica como gestualmente, la violencia ejercida contra las mujeres seguirá ocupando un lugar privilegiado dentro de la esfera privada. Hemos llegado a la conclusión de que sólo se podrá cambiar esta situación si los medios de comunicación asumen una nueva manera de trabajar, que algunos ya han iniciado pero que necesitan sistematizar y profundizar de forma rigurosa e inminente.

Junto a esto, la Universidad y la opinión pública juegan un papel primordial en la consecución de los objetivos marcados. La primera, para inculcar al alumnado de periodismo este manual de estilo, este protocolo de actuación ante este tipo de casos con el fin de que los futuros profesionales de la comunicación salgan ya de las aulas con esta destreza adquirida. La segunda, para generar una verdadera concienciación social contra esta lacra.

\section{REFERENCIAS}

Bordieu, P.(200). La dominación masculina. Barcelona: Anagrama.

Iortv. (2002). Mujer, Violencia y Medios de Comunicación Madrid: Dossier de Prensa.

Martínez Rodríguez, B.(2011). El tratamiento informativo de la violencia contra la mujer a la luz de los códigos deontológicos. Tesis doctoral. Facultad de Ciencias Sociales y de la Comunicación. Universidad de Vigo, España. 
Sánchez Aranda, J. J., Berganza, M. R. \& García Ortega, C. (2003). Mujer publicada, mujer maltratada. Libro de estilo para informar en los medios de comunicación sobre la mujer. Pamplona: Instituto Navarro de la Mujer.

San Martín J., Iborra I., García Y. \& Martínez P. (2010). III Informe Internacional. Violencia contra la mujer en las relaciones de pareja: Valencia, 2010. Serie Documentos

San Martín J. (2006, Marzo). II Informe Internacional: Violencia contra la mujer en las relaciones de pareja. Valencia: Centro Reina Sofía para el estudio de la violencia. Consultado el 14 de Marzo del 2010, Disponible en:

http://www.subsecar.cl/Estudios/CentroReinaSofia.pdf .

AlberdI, I. \& Matas, N. (2002, Marzo).La violencia doméstica. Informe sobe los malos tratos a mujeres en España. Barcelona: Fundación La Caixa (Colección Estudios Sociales, $\mathrm{n}^{\mathrm{o}}$ 10). Consultado el 12 de Marzo del 2011, Disponible en:

http:/ / obrasocial.lacaixa.es/StaticFiles/StaticFiles/6734192123ecf010VgnVCM2000 00128cf10aRCRD/es/es10_esp.pdf.

Berganza Conde, M.R. (2003, Febrero). La construcción mediática de la violencia contra las mujeres desde la Teoría del Enfoque. Comunicación y Sociedad, XVI: 2. Consultado el 14 de Febrero del 2010, Disponible en:

http://www.unav.es/fcom/comunicacionysociedad/es/articulo.php?art_id=97.

Indicadores. (2009). En: Centro de Investigaciones Sociológicas. Madrid, Consultado el 14 de Febrero del 2010, Disponible en:

http://www.cis.es/cis/opencms/Archivos/Indicadores/documentos_html/TresProb lemas.html

Entrevista con los lectores del país digital a Raimunda de Peñafort. Consultado el 19 de Noviembre del 2005, Disponible en:

http://www.elpais.com/edigitales/entrevista.html?encuentro=1849.

El Gobierno y las televisiones públicas crearán la figura del Defensor o Defensora de la Igualdad. (2005, Noviembre) En: Diario Público. Consultado el 19 de Noviembre del 2005, Disponible en:

http:/ / www.publico.es/espana/22497/el-gobierno-y-las-televisiones-publicascrearan-la-figura-del-defensor-o-defensora-de-la-igualdad/comentarios-valorados. Revisado el 04/02/2011.

Emitir en televisión medidas contra la violencia de género produce un efecto protector (2005, Noviembre). En: Servicio de Información de noticias científicas. Consultado el 19 de Noviembre del 2005, Disponible en:

http://www.plataformasinc.es/index.php/Noticias/Emitir-en-television-medidascontra-la-violencia-de-genero-produce-un-efecto-protector 
Flotats, A. (2009, 10 de Octubre). Informar sobre la violencia machista ayuda a prevenir nuevos crímenes. El País, p. 35.

Matey, P.(2008, 25 de Noviembre). El perfil del maltratador más violento. Madrid, 2008. El mundo. Consultado el 25 de Noviembre del 2008, Disponible en:

http:/ / www.elmundo.es/elmundosalud/2008/11/25/neurociencia/1227613365.ht

$\underline{\mathrm{ml}}$

ONU.(1993, Noviembre). Declaración sobre la eliminación de la violencia contra la mujer. Resolución de la Asamblea General 48/104 del 20 de diciembre de 1993. Consultado el 25 de Noviembre del 1993. Disponible en:

http://www.unhchr.ch/huridocda/huridoca.nsf/(symbol)/a.res.48.104.sp?opendocu $\underline{\text { ment }}$

Plan de trabajo para la igualdad entre las mujeres y los hombres 2006-2010. Comunicación de la Comisión al Consejo, al Parlamento Europeo, al Comité Económico y Social Europeo y al Comité de las Regiones. Consultado el 7 de Marzo del 2011, Disponible en:

http://eurlex.europa.eu/smartapi/cgi/sga_doc?smartapi!celexplus!prod!DocNum ber\&lg=es\&type_doc=COMfinal\&an_doc $=2006 \&$ nu_doc $=92$.

Rojas Torrijos, J. L.(2010, Enero). La responsabilidad social del informador en el uso del lenguaje ante la proliferación de hechos violentos en el mundo del deporte. Vivat Academia, Año XII(111). Consultado el 8 de Enero del 2010Disponible en:

http:// www.ucm.es/info/vivataca/numeros/n111/DATOSS.htm.

Sánchez Rodríguez, D. (2008). Violencia machista y medios de comunicación. El tratamiento informativo de los delitos relacionados con el maltrato a mujeres. Revista Comunicación y Hombre,(4), 3-15

Valencia, A. J. \& Palacio, M. C. (1999, Octubre). Historia de la violencia de género. Nuevos escenarios de la violencia contra la mujer. Colombia, 1999. Consultado el 7 de Enero de Octubre 2010, Disponible en:

http://www.umanizales.edu.co/programs/psicologia/Perspectivas/REVISTA\%202/ nuevosescenariosnuevosmaquillajes.pdf. ().

\section{Elena Bandrés Goldáraz}

Doctora por la Universidad de Navarra en Comunicación Pública y Licenciada en Ciencias de la Información por esta misma universidad. Su experiencia laboral ha ido siempre en paralelo con su inquietud académica. La revista Actualidad Económica, la agencia de noticias Europa Press TV, Antena 3 TV Aragón y, desde 2004, el Ayuntamiento de Zaragoza, son las empresas e instituciones en las que ha desempeñado su actividad laboral. Máster en Comunicación de Empresa y Publicidad de la Facultad de Ciencias Económicas y Empresariales de la Universidad de Zaragoza. 